\title{
Participatory science and directed survey methods: A case study with odontocetes in the Maui Nui region of the Hawaiian Islands
}

\author{
Marian Howe ${ }^{1,2,5}$, MARC O. LAMmers ${ }^{1,2,3}$ AND Robin W. BAIRD ${ }^{1,4}$ \\ Contacte-mail:mhowe@mmc.gov
}

\begin{abstract}
Given the difficulties and costs often associated with surveying cetaceans, enlisting members of the public to collect data offers a promising alternative approach. Comparison of cetacean 'participatory science' (also known as 'citizen science') data with data collected during traditional scientific studies helps reveal the strengths and weaknesses of a participatory science approach. With a large number of vessel operators on the water throughout the year, including dolphin-oriented tour boats, the Hawaiian Islands offer an ideal study site to employ such a dual-method comparison. The study aimed to enhance understanding of nearshore dolphin distributions relative to bathymetry. Operators of tour and fishing vessels within the shallow Maui Nui basin of the Hawaiian Islands were recruited to report delphinid sightings. Researchers conducted standard dolphin surveys within the same region. The participatory science approach was successful in generating a large sample size of sightings from five different species. Findings here demonstrate the potential value of participatory science and of using a multimethod approach to infer odontocete distribution trends relative to bathymetry in areas where both methods are feasible. Important refinements for future projects are highlighted.
\end{abstract}

KEYWORDS: CONSERVATION; DISTRIBUTION; INCIDENTAL SIGHTINGS; SURVEY-VESSEL; WHALE WATCHING

\section{INTRODUCTION}

'Participatory science', also known as citizen science, is a burgeoning field that uses volunteers to collect scientific information and help answer questions that otherwise would be logistically or financially infeasible (Bhattacharjee, 2005; Dickinson et al., 2010). In return, the public becomes more aware of conservation issues and gains a sense of 'earth stewardship' (Dickinson et al., 2012). As charismatic megafauna, cetaceans are the focus of many participatory science projects. These include shore-based monitoring studies to determine habitat use and temporal variation (Evans and Hammond, 2004; Pierpoint et al., 2009), using photos taken by tour operators or members of the public to help understand site fidelity via individual identification ((Baird et al., 2009; Baird et al., 2008), as well as stranding surveys to document mortality events and collect information on the basic biology of species (Ford et al., 1998; Gannon et al., 1997; MacLeod et al., 2005; Mignucci-Giannoni et al., 2000; Mignucci-Giannoni et al., 1999). Due to the ongoing popularity of marine mammal research programmes, some such as SeaWatch in the UK and the Great Whale Count in Hawai ${ }^{i} i$, have been occurring for decades. Given the costs and inherent difficulties of studying marine animals, tapping into a large-scale workforce of volunteers has resulted in greater spatiotemporal coverage of cetacean data, which, with appropriate analyses, can help inform policy and management decisions through a greater understanding of marine mammal biology and threats (Baird et al., 2002; Cheney et al., 2013; Ford et al., 1998; Gannon et al., 1997; Hauser et al., 2006; Weinrich et al., 2000).

However, participatory science cetacean studies are prone to numerous biases, and thus results must be critically evaluated when drawing inferences. Accurate taxonomic identification is an inherent requirement for wildlife studies, but this is often difficult to achieve with participatory science research as similar species can often be confused (Bell, 2006), and this is certainly the case with cetaceans in Hawai ${ }^{\circ} \mathrm{i}$ (Baird, 2016). Non-random distributions of volunteer effort and under-detection of species may also skew data (Bird et al., 2014; Crall et al., 2011; Robinson et al., 2018). However, when these biases are controlled in the initial design of participatory science studies and when volunteers are supervised by researchers, accurate data can be collected (Delaney et al., 2008).

In the absence of direct supervision of volunteers, the accuracy of participatory science data usually requires validation that it meets a certain standard (Bird et al., 2014), yet only about half of published participatory science studies include some sort of verification process to ensure data quality (Thiel et al., 2014). Furthermore, only one cetacean study has compared frequency of dolphin sightings made by volunteers to those made during directed surveys (Bristow et al., 2001). To address the issue of data quality, some cetacean studies have compared and combined several independent approaches, allowing for estimation of biases by method and strengthening scientific conclusions (Baird et al., 2002; Cheney et al., 2013).

Numerous opportunities exist to enhance the capabilities of cetacean participatory science projects to produce more comprehensive and robust scientific data. Captains and crew of commercial vessels offer a valuable resource to marine mammal studies, as they are generally familiar with their local waters and marine fauna and thus may more accurately identify species. In addition, data such as sighting

\footnotetext{
${ }^{1}$ Hawai 'i Institute of Marine Biology, University of Hawai 'i, PO Box 1348, Kaneohe, Hawai 'i 96744.

${ }^{2}$ Oceanwide Science Institute, PO Box 61692, Honolulu, Hawai 'i 96839.

${ }^{3}$ Hawaiian Islands Humpback Whale National Marine Sanctuary, 726 S. Kihei Rd., Kihei, Hawai i 96753.

${ }^{4}$ Cascadia Research Collective, 2181/2 W. $4^{\text {th }}$ Avenue, Olympia, Washington 98501.

${ }^{5}$ Marine Mammal Commission, 4340 East-West Hwy., Rm. 700, Bethesda, Maryland 20814.
} 
coordinates collected by volunteers on vessels may be analysed post-hoc relative to other biological data such as water depth to better understand cetacean habitat preference. Mobile technology also holds great potential in participatory science projects as an easy, cost-efficient, real-time communication tool to help facilitate data collection and reporting (Baker and Oeschger, 2009). The widespread use of Short Message Service (SMS) text messages has helped streamline marine field efforts, with texts now used to relay information from tagged animals as well as to report catch and effort information from fishermen (Baker and Oeschger, 2009; Cronin and McConnell, 2008; McConnell et al., 2004).

Around the Hawaiian Islands, historically much of the cetacean science by both citizens and experts has centered on the humpback whale (Megaptera novaeangliae). Until recently, most odontocete species have received comparatively little attention (Baird, 2016; Baird et al., 2013). While many single species studies have been conducted around the islands, including research on common bottlenose dolphins (Tursiops truncatus; hereafter bottlenose dolphins) (Baird et al., 2009), pantropical spotted dolphins (Stenella attenuata) (Baird et al., 2001; Courbis et al., 2014), spinner dolphins (Stenella longirostris) (Benoit-Bird and Au, 2003; Lammers, 2004; Norris et al., 1994; Thorne et al., 2012), false killer whales (Pseudorca crassidens) (Baird et al., 2008; Baird et al., 2010), and short-finned pilot whales (Globicephala macrorhynchus) (Abecassis et al., 2015; Mahaffy et al., 2015; Van Cise et al., 2017), relatively few comprehensive, systematic multispecies assessments have been made of the eighteen odontocete species known to inhabit Hawaiian waters (Baird, 2016; Barlow, 2006).

Since 2000, there has been an ongoing multispecies assessment of odontocetes around the main Hawaiian Islands
(Baird, 2016; Baird et al., 2013). Among other findings, these results showed that the sighting rates of most species varied with depth, with some species such as spinner dolphins most often found in depths less than 1,000m and other species such as rough-toothed dolphins (Steno bredanensis) commonly using depths greater than $3,000 \mathrm{~m}$ (Baird et al., 2013). However, relatively little effort was made in the shallow basin of the Maui Nui region (Maui, Lāna'i, Moloka'i, Kaho'olawe; see Fig. 1), an area of high commercial tour vessel traffic. Thus, this area remains understudied with much still to be described and learned about how odontocetes use this distinct local environment. Bathymetry is an important criterion of habitat selection for many delphinids, related to, for example, enhanced foraging success or refuge from predators (Davis et al., 2002; Davis et al., 1998; Hastie et al., 2004; Thorne et al., 2012). Thus understanding the interspecific distribution of delphinids in this shallow water region of substantial human activity can help guide odontocete management.

This study implemented a participatory science delphinidsighting project in the Maui Nui region, capitalising on the numerous vessel crew and captains operating in the region to report odontocete sightings around the four islands. In addition, existing odontocete observations collected via dedicated surveys by Baird et al. (2013) and the Cascadia Research Collective around Maui and Lāna'i allowed for a comparative analysis of the two methods, increasing confidence in our understanding of delphinid distributions in insular Hawaiian waters.

\section{METHODS}

At the beginning of June 2015, the captains and/or crew members of sport fishing and commercial tour vessel

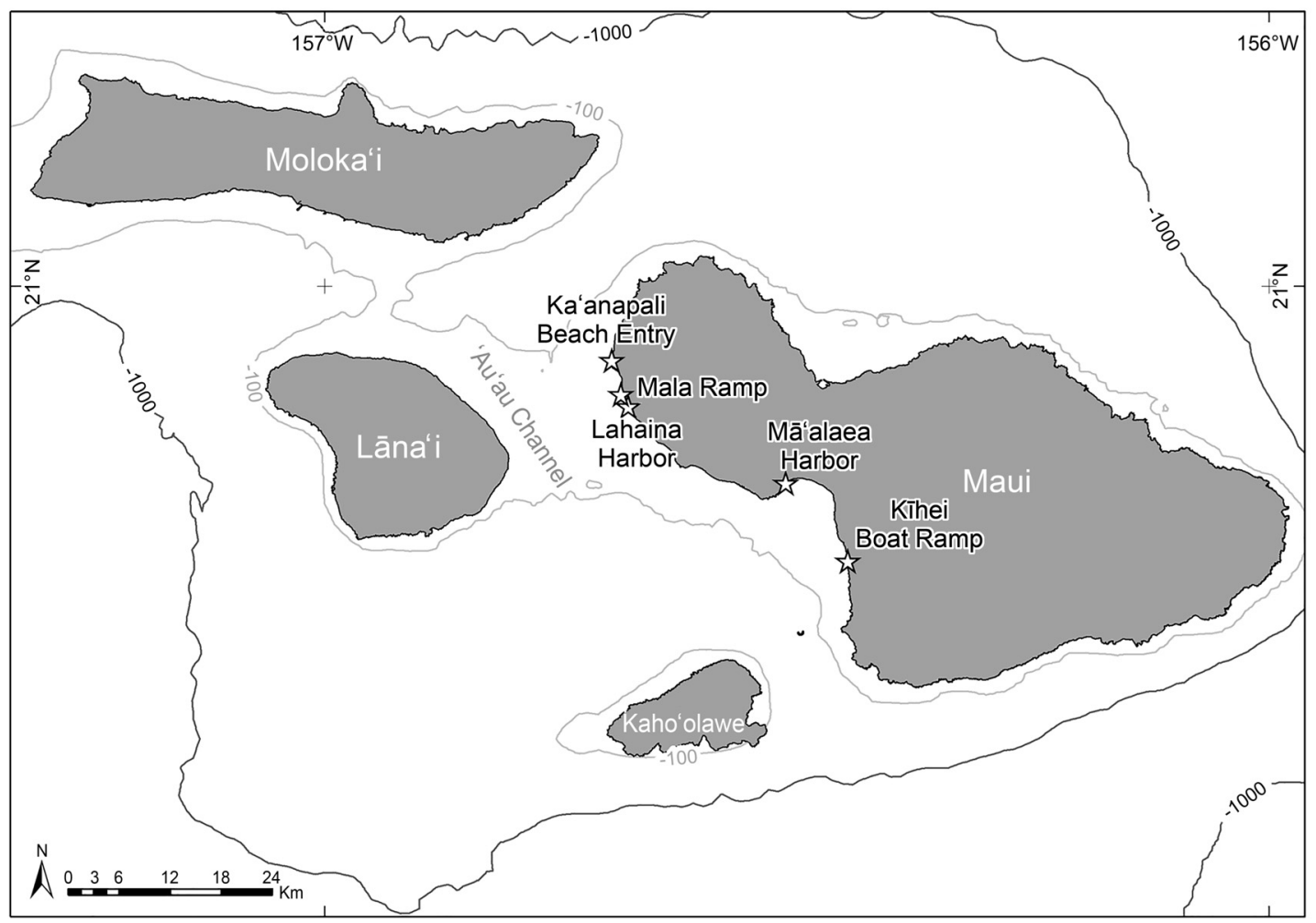

Fig. 1. Reference map of the Maui Nui region. Harbours are displayed on the map where volunteer participation in the community science project was solicited. The $100 \mathrm{~m}$ isobath is shown in light gray, and the $1,000 \mathrm{~m}$ isobath is shown in dark gray. 
operators were approached at launch ramps and harbours along the leeward coast of Maui, including the Kihei Boat Ramp, Mā'alaea Harbor, Lahaina Harbor, Mala Boat Ramp and $\mathrm{K} \bar{a}$ 'anapali Beach Entry. Each harbour was visited once between the hours of 14:00 and 16:00 from 1 June 2015 and 15 June 2015, and during that time period, researchers attempted to approach and talk to personnel associated with every tour or fishing vessel present at the docks/ramps. The purpose of the community sighting project and the ecological importance of odontocetes were explained and discussed with the crew. If a captain or crew member expressed interest in participating in the project, he/she was given a laminated protocol sheet that gave the project goals and procedures. The protocol asked for several key pieces of information whenever a delphinid group was sighted in the Maui Nui region, including: (1) the date, the time of day and the GPS coordinates of the vessel; and (2) an identification of the species using a dorsal fin photo key of the most common species in the area, which included spinner dolphins, bottlenose dolphins, pantropical spotted dolphins, false killer whales and short-finned pilot whales. It was requested that all sighting information be communicated via SMS text messages. If an observer was uncertain about the identity of the species, they were encouraged to send photos of the sighting along with the data. No permits were required for the citizen science effort, as all vessel operators observed passively and were assumed to abide by the approach regulations set forth by the Marine Mammal Protection Act (MMPA). Although we cannot verify the behaviour of the vessels involved in this study, the authors have not witnessed any blatant violations of the MMPA by vessel operators in the Maui Nui region. The project lasted for six months through November 2015. Updates and reminders were periodically communicated to all observers involved in the project.

In addition, sighting data were used from Baird et al. (2013) from odontocete surveys conducted by the Cascadia Research Collective in the leeward Maui Nui region in 2000, 2001, 2002, 2003 and 2012. Survey areas had been chosen to maximise geographic scope and depth range within Maui Nui, while remaining in areas with relatively calm conditions with minimal swell (Beaufort Sea State $<3$ ). While on survey effort, two to six observers scanned 360 degrees around the vessel primarily with the naked eye and occasionally with binoculars. When an odontocete group was spotted, the group was approached for identification and GPS coordinates and time of day were recorded. In addition, photographs were taken for most encounters for photoidentification catalogues (Baird et al., 2009; Baird et al., 2008; Mahaffy et al., 2015).

All sightings from both survey approaches were compiled and filtered. Species that were observed only once using either method were omitted from the analysis. In addition, sightings were excluded if they were made outside the $1,000 \mathrm{~m}$ isobath, the designated edge of the Maui Nui region in this study. Sightings reported with approximate locations, such as 'Manele Bay,' were still included in the analyses, and GPS coordinates were estimated for the location. To ensure the independence of each community project sighting, all sightings reported for the same species occurring within a $5 \mathrm{~km}$ radius during the same hour on the same day as another sighting were discarded. Sightings were plotted using the $\mathrm{R}$ package 'ggmap' (Kahle and Wickham, 2013). With the restricted sighting information, water depths were generated for each encounter using the GPS coordinates input in the 'get.depth' function from the R package 'marmap'. Depths of sightings from the participatory science approach were compared with those from the standard surveys across all observed odontocete species using an unpaired two-sample test. The specific test, either a parametric Student's t-test or a non-parametric Wilcoxon rank sum test, was determined on the basis of the normality of the data visually assessed via QQ plots. Data were then pooled across methods and median depths of sightings were examined relative to species.

\section{RESULTS}

Thirty vessels were approached during the two-week solicitation period in early June 2015, and by the end of the project in November 2015, 37 observers representing 24 different vessels ( $80 \%$ response rate) had provided sightings of delphinids. The vessels included 19 commercial tour operators and five sport-fishing operations. Observers reported 320 total sightings of six species including bottlenose dolphins, spinner dolphins, pantropical spotted dolphins, false killer whales, short-finned pilot whales and melon-headed whales (Peponocephala electra). Half of the sightings came from three observers, while the mean number of sightings for the other 34 observers was considerably lower $(\overline{\mathrm{x}}=4.3, \mathrm{SD}=3.7)$. When observations were corrected for duplicate sightings, the total number of sightings decreased to 276 independent reports (Fig. 2). Sightings were made between 06:00 and 18:00. Only one sighting was made of melon-headed whales so the species was removed from the depth analysis. The most frequently sighted species were spinner dolphins $(n=151)$ followed by bottlenose dolphins $(n=83)$ and pantropical spotted dolphins $(n=30)$, while short-finned pilot whales $(n=5)$ and false killer whales $(n=7)$ were the least often sighted (Fig. 3). July had the greatest number of observations $(n=97)$, with reporting effort diminishing each subsequent month until the end of the project.

There were 111 sightings of eight odontocete species from the Maui Nui region in the Baird et al. (2013) surveys. In addition to the six species observed by the community observers, these included rough-toothed dolphin (Steno bredanensis) and dwarf sperm whale (Kogia sima). As with the community project, sightings were made during the hours of 06:00 and 18:00. Only one sighting was made each of melon-headed whales, rough-toothed dolphins and dwarf sperm whales, so these three species were excluded from further analysis relative to depth. Across all surveys, the most commonly observed species was the bottlenose dolphin $(n=60)$, while false killer whales $(n=4)$ and spinner dolphins $(n=9)$ were the least sighted (Fig. 4), in contrast with the large number of spinner dolphin reports from the participatory science efforts.

Distributions of depths of sightings were skewed for most species, and thus a two-tailed non-parametric Wilcoxon rank sum test was chosen to compare sighting depths between the directed survey approach and the community sighting project for each species. Test results showed that the two approaches produced significantly different sighting depths of spinner dolphins $(W=1068, p=0.001)$ and short-finned pilot 

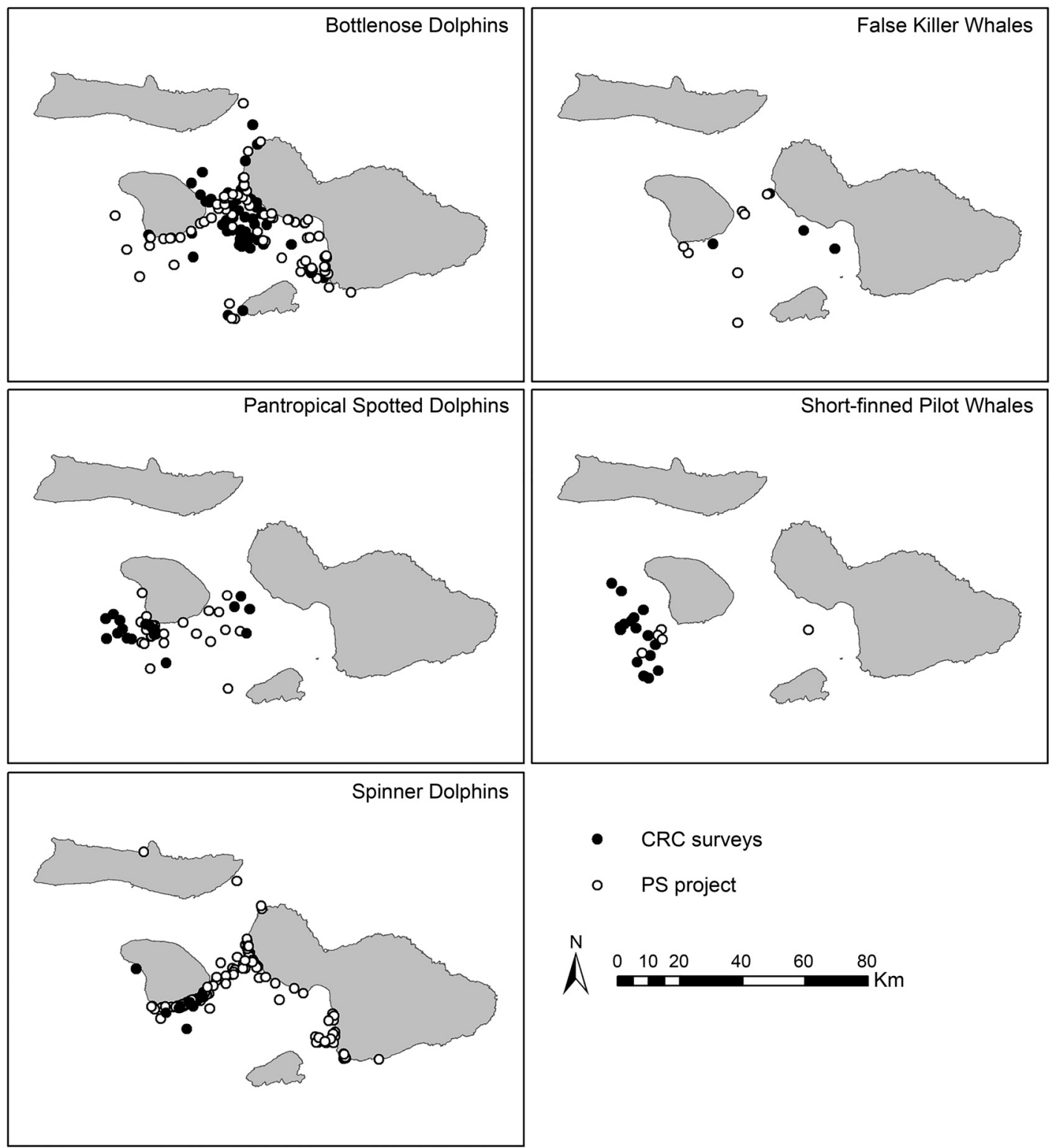

Fig. 2. Map of odontocete sightings from the Cascadia Research Collective (CRC) surveys $(n=108)$ and Participatory Science (PS) project $(n=276)$ in the Maui Nui region. Observations were corrected for replicate sightings and exclude species sighted only once.

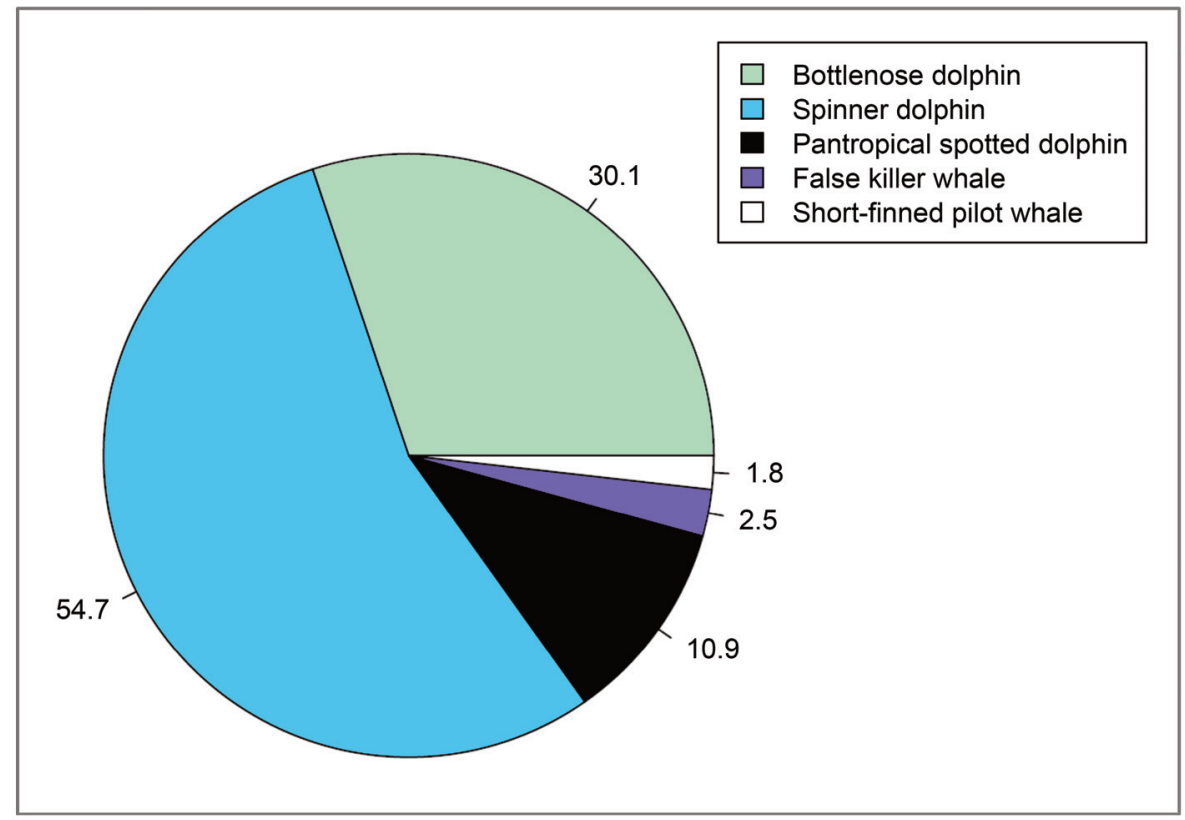

Fig. 3. Sighting proportions of odontocete species in the Maui Nui region based on the Participatory Science project. Slices are labeled with percentages representing the proportion of observations of each species. 


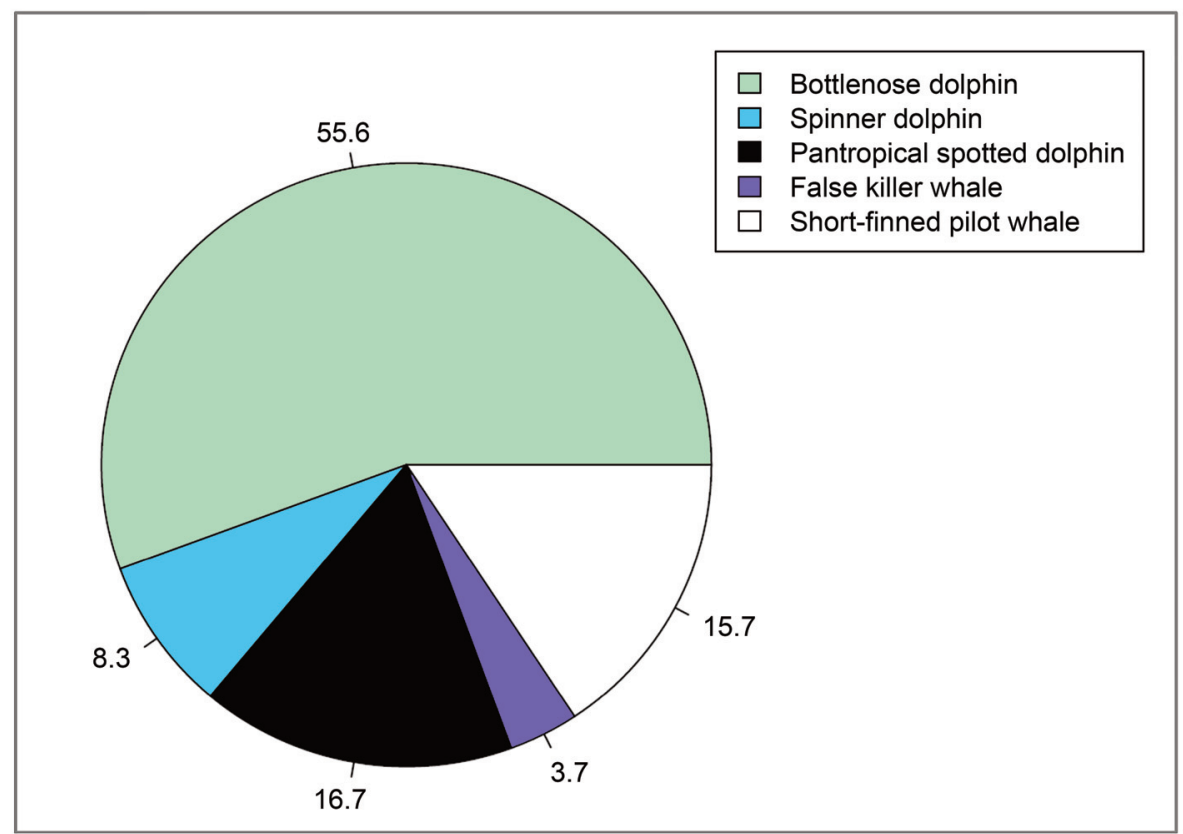

Fig. 4. Sighting proportions of odontocete species in the Maui Nui region based on the Cascadia Research Collective surveys. Slices are labeled with percentages representing the proportion of observations of each species.

Table 1

Hodges-Lehmann estimators of depth of sightings $(\mathrm{m})$ by method. 95\% confidence intervals are shown in parentheses. $* 88 \%$ confidence intervals shown. $\mathrm{CRC}=$ Cascadia Research Collective; PS = Participatory Science

\begin{tabular}{lccrr}
\hline & \multicolumn{2}{c}{ CRC surveys } & \multicolumn{2}{c}{ PS project } \\
\cline { 2 - 5 } \multicolumn{1}{c}{ Species } & Sample size & Depth of sighting (m) & Sample size & Depth of sighting (m) \\
\hline Bottlenose dolphin & 60 & $102.5(81.5-125.5)$ & 83 & $86.5(67.5-107.5)$ \\
Spinner dolphin & 9 & $167.0(88.0-257.0)$ & 151 & 71.5 \\
False killer whale & 4 & $89.8(62.5-80.0)$ & $173.8(61.5-302.0)$ \\
Pantropical spotted dolphin & 18 & $387.5(276.0-506.5)$ & 30 & $272.0(214.5-327.5)$ \\
Short-finned pilot whale & 17 & $676.0(637.0-702.0)$ & 5 & $452.8(411.0-668.0)^{*}$ \\
\hline
\end{tabular}

whales $(W=60, p=0.007)$, with directed surveys sighting pilot whales and spinner dolphins in deeper waters than community observers (Fig. 4). However, for the other three species, there were no significant depth differences between the two survey types $\left(W_{\text {bottlenose }}=2,766 p=0.1614\right.$, $W_{\text {spotted }}=351 p=0.0862, W_{\text {falsekiller }}=10.5 \mathrm{p}=0.5699$; Table 1). For both methods, pilot whales were seen in the deepest waters (Table 1; Fig. 4), while pantropical spotted dolphins were found in intermediate depths. The other three species (bottlenose dolphins, spinner dolphins, and false killer whales) were all observed in relatively similar, shallower waters of approximately $80 \mathrm{~m}$.

\section{DISCUSSION}

The Maui Nui delphinid community sighting project was successful in generating a large data set of odontocete sightings from five different species and laying a groundwork for future studies in the region. The request for minimal sighting information combined with the ease of text message reporting likely contributed to participation by many different vessel operators and the large number of observations that were received. Reporting was initially high during the beginning of the project and peaked a month after its start date; reported sightings steadily decreased over the course of the project. Given that several of the populations are known to be resident to the area (Baird, 2016), this decrease is probably a reflection of diminished reporting over time, with crew occupied by other responsibilities and/or forgetting to report. Sharing unusual sightings with all volunteers or creating reporting incentives, such as prizes for the most sightings (Hochachka et al., 2012), may help maintain reporting levels for future projects.

Species identification is of critical importance to this study and identification ability may not be consistent across all volunteers (Falk et al., 2019); mistakes may be more prevalent for species of similar appearance (e.g. spinner and spotted dolphins). However, the few observers that submitted the majority of the reports may have initially been more interested in marine science and/or delphinids (Thiel et al., 2014) and it is possible that they were more knowledgeable of the dolphin species in the region and thus to more likely to provide accurate reports.

When the depth data for the participatory science project were compared with those from directed surveys, there was little difference for three of the five species (bottlenose and pantropical spotted dolphins, false killer whales) although sample sizes for the last species were small in both cases ( $n=4$ and 7, respectively). This similarity provides support for the participatory science approach as well as the results from the directed approach relative to bathymetry, at least in the areas where observers regularly spend time. However, spinner dolphins and short-finned pilot whales were sighted 


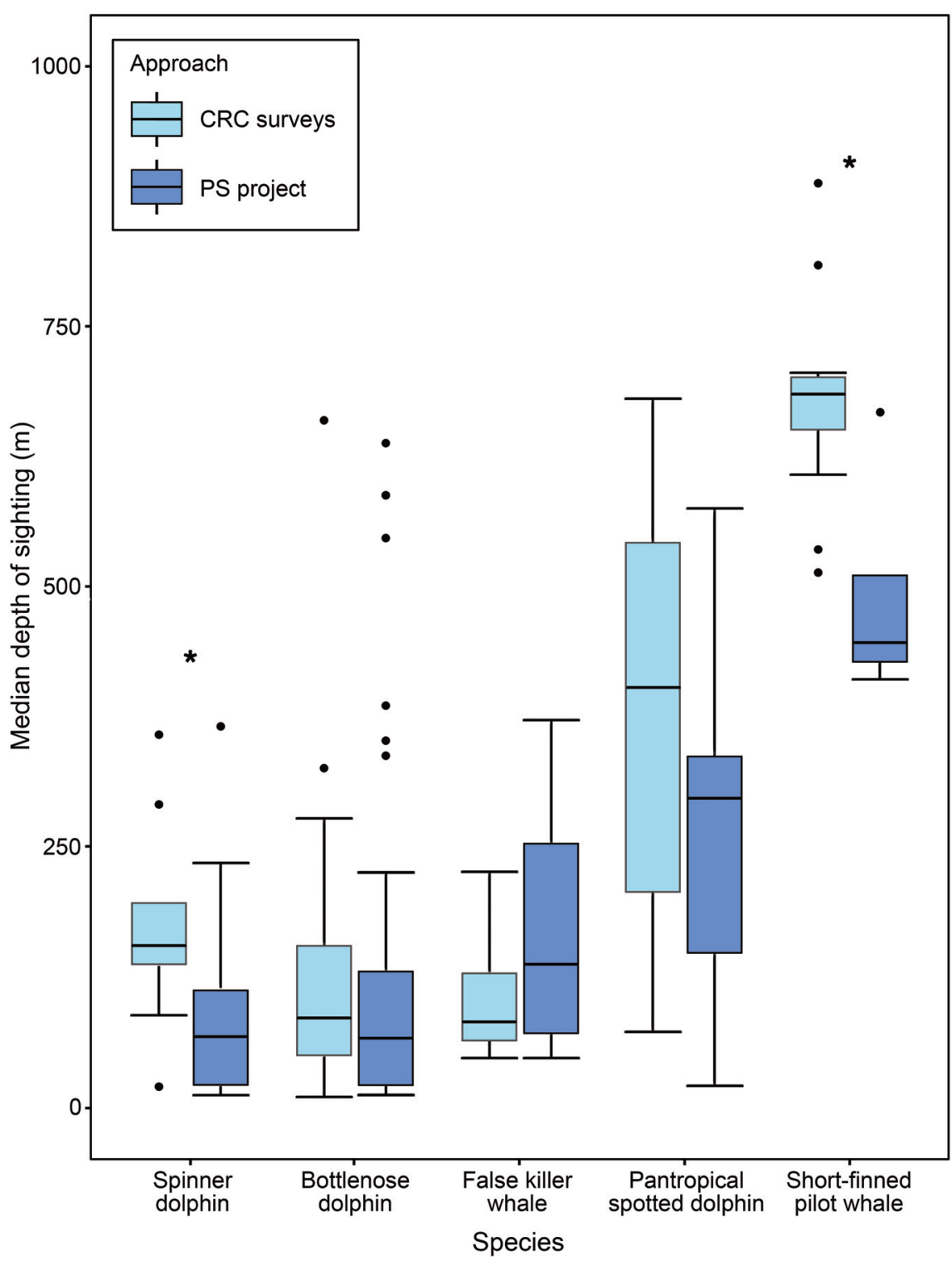

Fig. 5. Comparisons of depth of sighting $(\mathrm{m})$ by survey type. The middle line in each box represents the median, the box designates Q1 and Q3, and the ends of the whiskers mark the minimum and maximum values within the ' 1.5 rule'. Points represent outliers that are either less than Q1-1.5*IQR or greater than $\mathrm{Q} 3+1.5 * \mathrm{IQR}$. * = Indicates significant difference between Hodges-Lehmann estimators at $\mathrm{p}=0.05$ based on Wilcoxon rank sum tests. $\mathrm{CRC}=$ Cascadia Research Collective; $\mathrm{PS}=$ Participatory Science.

in depths that were significantly different between the directed surveys and the community sighting effort, with the former observing both species in deeper waters. The two species also comprised different proportions of the total delphinid sightings for the two surveys approaches, likely due to different distributions of effort. For example, to find spinner dolphins for their passengers, tour operators often transit across relatively shallow depths and search in shallow near-shore areas, since spinner dolphins are known to occupy shallow coastal areas during the daytime (Lammers, 2004; Norris et al., 1994; Thorne et al., 2012).

In contrast, the Baird et al. (2013) surveys in the Maui Nui region targeted less common odontocete species and thus took place farther away from the coastline. This accounts for the relatively small sample size of spinner dolphin observations from these surveys. For pilot whales, different distributions of effort probably led to the considerable difference in total sightings, with participatory science vessels typically not transiting near the majority of the Baird et al. (2013) pilot whale sightings along the slope of Maui Nui. Indeed, all participatory science pilot whale observations were opportunistically made by fishing vessels, which engage in more offshore transits than tour operators. A larger sample size of participatory science pilot whale sightings, including more observations from fishing vessels, may have produced results more similar to the directed surveys. Non-random distributions of effort can be an issue with participatory science projects (Crall et al., 2011), and this bias was apparent in the community sighting approach. On the other hand, the Baird et al. (2013) directed surveys were conducted farther away from the coastline in deeper waters, and thus this sampling approach likely captured the preferred depths of some, but not all the common dolphin species. The results suggest that comprehensive participatory science projects would need to direct effort over both deep and shallow waters of the archipelago. 
In the past, a variety of methods have been used to assess habitat use of odontocetes around the main Hawaiian Islands, including sighting surveys, satellite tagging and acoustic monitoring. Depending on the species being studied there are advantages and disadvantages to each method. For rarely seen species, such as beaked whales, satellite tagging and acoustic monitoring may be the most useful approaches (e.g. Abecassis et al., 2015; Baird, 2016; Schorr et al., 2009). Both of these approaches are also particularly valuable in areas with consistently strong winds and poor sighting conditions, as tagged animals may be tracked as they move into areas difficult to access by vessel, and dolphin movement patterns may be acoustically monitored using hydrophones within these areas. Participatory science approaches similar to the one presented here are likely to be most valuable in areas of high vessel activity, relatively good viewing conditions and in areas used extensively by the species of interest, provided the species are relatively easy to identify (Bell, 2006).

While the preferred depth ranges of the species presented here have been relatively well established throughout the Hawaiian Islands (Baird et al., 2015; Baird et al., 2010; Baird et al., 2013; Thorne et al., 2012), the results of this study contribute useful scientific information regarding the daytime depth ranges most used within the Maui Nui region. With some knowledge of these preferred daytime depths, spatial distributions of odontocete populations, both resident and non-resident, around the basin may also begin to be inferred. Based on the observed means, these results also complement and further elucidate passive acoustic monitoring in the Maui Nui region, which revealed diel distribution differences relative to bathymetry between larger-bodied odontocetes and smaller species. Based on this study, as well as results from satellite tagging efforts and surveys from throughout the main Hawaiian Islands (Baird, 2016), pilot whales appear to primarily occupy deeper insular waters, likely in order to forage more efficiently on their epipelagic squid prey (Abecassis et al., 2015; Pauly et al., 1998). In contrast, within the Maui Nui basin, false killer whales do use the shallower depths, reflecting that their prey, which consists of larger fish such as mahi mahi (Coryphaena hippurus) and tuna (Thunnus sp.) (Baird et al., 2008; Connor and Norris, 1982; Shallenberger, 1981), also use these shallow waters. Individual false killer whales from the insular population may also use shallow waters to capture prey more efficiently, i.e. they may be able to leverage the bottom to limit their prey's ability to escape to greater depths beyond their reach. Interestingly, based on both nearshore and offshore surveys as well as satellite tagging data, false killer whales from this population also use habitat beyond the island shelf of depths up to nearly $5,000 \mathrm{~m}$ (Baird et al., 2012; Baird et al., 2010), revealing the importance of the spatial scale considered when assessing results.

The three other species sighted during this study, the smaller pantropical spotted dolphins, bottlenose dolphins and spinner dolphins, were found in mid- to shallow-depth ranges during the daytime. Based on acoustic monitoring results in the Maui Nui basin, these smaller species typically prefer coastal habitats that are in close proximity to the $1,000 \mathrm{~m}$ contour, particularly during the nighttime. This likely enables efficient foraging on the productive mesopelagic boundary layer of micronekton that migrates towards shore during nighttime hours (Benoit-Bird and Au, 2003; Reid et al., 1991). It may also be inferred that areas farther out from the island shelf may offer limited protection and prey resources for small delphinids and therefore represent less desirable resting and foraging habitats. The results of this study show that spotted dolphins, sighted at mid-depth ranges, do not rely as heavily on shallow resting areas during the day and instead occupy deeper water coastal areas for resting. Off other islands in the archipelago spotted dolphins can also be found in deeper offshore areas (Baird, 2016; Baird et al., 2013). In contrast, spinner dolphins appear to depend on shallow water habitats during the daytime, which is consistent with prior research on spinner dolphins (Norris and Dohl, 1980; Norris et al., 1994; Thorne et al., 2012). Many of the sightings of spinner dolphins between Maui and Lāna' $i$ in the 'Au'au Channel (Fig. 2) were likely either groups transiting between shallow-water resting areas adjacent to one or the other islands or resting within the relatively shallow waters of the channel.

In summary, certain biases are inevitable in any participatory science project but they can be better estimated and assessed when the results are examined in light of those from directed scientific studies (Baird et al., 2002) and integrated into larger efforts to characterise species distributions. In addition, using a multi-method approach, even with the presence of confounding factors, may provide greater confidence in the overall results than if only one method was used. For cetacean studies, further comparison of results with those generated using approaches with better temporal or spatial coverage (e.g. passive acoustic monitoring or satellite tagging) should further contribute to a better understanding of the overall system. Future cetacean participatory science projects should leverage volunteers such as fishermen and other vessel operators who possess valuable knowledge of their marine environments and understand local delphinid distribution patterns. Vessel captains and crew may also occasionally sight rare and unusual cetaceans, which is valuable information that often remains undocumented.

Improvements could also be made to future participatory science projects based on the results of this work. Along with using an incidental sighting methodology, such as the one used in this project, participatory science cetacean studies could also make an effort to measure the level of effort expended by volunteers and the geographical extent of their observations in order to generate rates of observations and further expand the utility of the data. In addition, with greater personnel support to help develop and implement participatory science projects, training sessions could be provided to all volunteer recruits in order to uniformly prepare volunteers for their tasks, thereby raising levels of participation. Finally, the specific tools used for data collection and communication have been shown to be a critical factor determining the success or failure of self-reporting programmes (McCluskey and Lewison, 2008). Therefore, participatory science projects should aim to utilise user-friendly technologies such as smartphone apps or SMS text messages that facilitate the transmission of data from volunteers to coordinators. 


\section{ACKNOWLEDGEMENTS}

The authors would like to thank all Maui Nui vessel operators who contributed to the community delphinid sighting project, with particular thanks to Rob Schoenherr, Lynn Padilla and Jason Kerber for providing half of all sightings. In addition, we would like to thank Allan Ligon, Daniel Webster, Sascha Hooker, and other Cascadia Research Collective staff and volunteers who participated in survey efforts around the Maui Nui region, as well as funding and/or support for those studies from the Hawaiian Islands Humpback Whale National Marine Sanctuary, the Hawai'i Ocean Project, Hawai'i Wildlife Fund, US Navy Pacific Fleet, and the Southwest Fisheries Science Center. We would also like to thank Anke Kuegler for her assistance in the production of the maps. Finally, we would like to thank Eric Pante, creator of the R package 'marmap,' for his assistance with the functions utilised in this study.

\section{REFERENCES}

Abecassis, M., Polovina, J., Baird, R.W., Copeland, A., Drazen, J.C., Domokos, R., Oleson, E., Jia, Y., Schorr, G.S., Webster, D.L. and Andrews, R.D. 2015. Characterizing a foraging hotspot for short-finned pilot whales and Blainville's beaked whales located off the west side of Hawai' $i$ Island by using tagging and oceanographic data. PLoS ONE 10(11): e0142628.

Baird, J.W., Ligon, A.D., Hooker, S.K. and Gorgone, A.M. 2001. Subsurface and night time behaviour of pantropical spotted dolphins in Hawaii. Can. J. Zool. - Rev. Can. Zool. 79: 988-96.

Baird, R.W. 2016. The Lives of Hawai ' $i$ 's Dolphins and Whales: Natural History and Conservation. University of Hawai 'i Press, Honolulu, 352pp.

Baird, R.W., Cholewiak, D., Webster, D.L., Schorr, G.S., Mahaffy, S.D., Curtice, C., Harrison, J. and Van Parijs, S.M. 2015. Biologically important areas for cetaceans within US waters. Aquat. Mamm. 41: 54-64.

Baird, R.W., Gorgone, A.M., McSweeney, D.J., Ligon, A.D., Deakos, M.H., Webster, D.L., Schorr, G.S., Martien, K.K., Salden, D.R. and Mahaffy, S.D. 2009. Population structure of island-associated dolphins: evidence from photo-identification of common bottlenose dolphins (Tursiops truncatus) in the main Hawaiian Islands. Mar. Mamm. Sci. 25: 251-74.

Baird, R.W., Gorgone, A.M., McSweeney, D.J., Webster, D.L., Salden, D.R., Deakos, M.H., Ligon, A.D., Schorr, G.S., Barlow, J. and Mahaffy, S.D. 2008. False killer whales (Pseudorca crassidens) around the main Hawaiian Islands: long-term site fidelity, inter-island movements, and association patterns. Mar. Mamm. Sci. 24(3): 591-612.

Baird, R.W., Hanson, M.B., Schorr, G.S., Webster, D.L., McSweeney, D.J., Gorgone, A.M., Mahaffy, S.D., Holzer, D.M., Oleson, E.M. and Andrews, R.D. 2012. Range and primary habitats of Hawaiian insular false killer whales: informing determination of critical habitat. Endang. Species Res. 18: 47-61.

Baird, R.W., Schorr, G.S., Webster, D.L., McSweeney, D.J., Hanson, M.B. and Andrews, R.D. 2010. Movements and habitat use of satellite-tagged false killer whales around the main Hawaiian Islands. Endang. Species Res. 10: 107-21.

Baird, R.W., Stacey, P.J., Duffus, D.A. and Langelier, K.M. 2002. An evaluation of gray whale (Eschrichtius robustus) mortality incidental to fishing operations in British Columbia, Canada. J. Cetacean Res. Manage. 4(3): 289-96.

Baird, R.W., Webster, D.L., Aschettino, J.M., Schorr, G.S. and McSweeney, D.J. 2013. Odontocete cetaceans around the main Hawaiian islands: habitat use and relative abundance from small-boat sighting surveys. Aquat. Mamm. 39: 253-69.

Baker, M.S.J. and Oeschger, I. 2009. Description and initial evaluation of a text message based reporting method for marine recreational anglers. Mar. Coast. Fish. 143-154. [Available at: https://doi.org/10.1577/ C08-042.1]

Barlow, J. 2006. Cetacean abundance in Hawaiian waters estimated from a summer/fall survey in 2002. Mar. Mamm. Sci. 22(2): 446-64.

Bell, J.J. 2006. The use of volunteers for conducting sponge biodiversity assessments and monitoring using a morphological approach on IndoPacific coral reefs. Aquat. Conserv. 17(2): 133-45.

Benoit-Bird, K.J. and Au, W.W.L. 2003. Prey dynamics affect foraging by a pelagic predator (Stenella longirostris) over a range of spatial and temporal scales. Behav. Ecol. Sociobiol. 53(6): 364-73.

Bhattacharjee, Y. 2005. Citizen scientists supplement work of Cornell researchers. Science 308(5727): 1,402-03.
Bird, T.J., Bates, A.E., Lefcheck, J.S., Hill, N.A., Thomson, R.J., Edgar, G.J., Stuart-Smith, R.D., Wotherspoon, S., Krkosek, M., Stuart-Smith, J.F., Pecl, G.T., Barrett, N. and Frusher, S. 2014. Statistical solutions for error and bias in global citizen science datasets. Biol. Cons. 173: 14454.

Bristow, T., Glanville, N. and Hopkins, J. 2001. Shore-based monitoring of bottlenose dolphins (Tursiops truncatus) by trained volunteers in Cardigan Bay, Wales. Aquatic Mammals 27(2): 115-20.

Cheney, B., Thompson, P.M., Ingram, S.N., Hammond, P.S., Stevick, P.T., Durban, J.W., Culloch, R.M., Elwen, S.H., Mandleberg, L., Janik, V.M., Quick, N.J., Islas-Villanueva, V., Robinson, K.P., Costa, M., Eisfeld, S.M., Walters, A., Phillips, C., Weir, C.R., Evans, P.G.H., Anderwald, P., Reid, R.J., Reid, J.B. and Wilson, B. 2013. Integrating multiple data sources to assess the distribution and abundance of bottlenose dolphins Tursiops truncatus in Scottish waters. Mammal Rev. 43(1): 71-88.

Connor, R.C. and Norris, K.S. 1982. Are dolphins reciprocal altruists? The American Naturalist 119(3): 358-74.

Courbis, S., Baird, R.W., Cipriano, F. and Duffield, D. 2014. Multiple populations of pantropical spotted dolphins in Hawaiian waters. J. Hered. 105: $627-41$.

Crall, A.W., Newman, G.J., Stohlgren, T.J., Holfelder, K.A., Graham, J. and Waller, D.M. 2011. Assessing citizen science data quality: an invasive species case study. Cons. Letts 4: 433-42.

Cronin, M.A. and McConnell, B.J. 2008. SMS seal: A new technique to measure haul out behaviour in marine vertebrates. J. Exp. Mar. Biol. Ecol. 362: 43-48.

Davis, P.W., Ortega-Ortiz, J.G., Ribic, C.A., Evans, W.E., Biggs, D.C., Ressler, P.H., Cady, R.B., Leben, R.R., Mullin, K.D. and Würsig, B. 2002. Cetacean habitat in the northern oceanic Gulf of Mexico. Deep-Sea Research I 49: 121-43.

Davis, R.W., Fargion, G.S., May, N., Leming, T.D., Baumgartner, M., Evans, W.E., Hansen, L.J. and Mullin, K. 1998. Physical habitat of cetaceans along the continental slope in the north-central and western gulf of Mexico. Mar. Mamm. Sci. 14(3): 490-507.

Delaney, D.G., Sperling, C.D., Adams, C.S. and Leung, B. 2008. Marine invasive species: validation of citizen science and implications for national monitoring networks. Biol. Invasions 10: 117-28.

Dickinson, J.L., Shirk, J., Bonter, D., Bonney, R., Crain, R.L., Martin, J., Phillips, T. and Purcell, K. 2012. The current state of citizen science as a tool for ecological research and public engagement. Frontiers Ecol. Environ. 10: 291-97.

Dickinson, J.L., Zuckerberg, B. and Bonter, D.N. 2010. Citizen science as an ecological research tool: challenges and benefits. Annu. Rev. Ecol. Evol. S. 41: 149-72.

Evans, P.G.H. and Hammond, P.S. 2004. Monitoring cetaceans in European waters. Mammal Rev. 34(1): 131-56.

Falk, S., Foster, G., Comont, R., Conroy, J., Bostock, H., Salisbury, A., Kilbey, D., Bennet, J. and Smith, B. 2019. Evaluating the ability of citizen scientists to identify bumblebee (Bombus) species. PLOS ONE 14: e0218614.

Ford, J.K., Ellis, G.M., Barrett-Lennard, L.G., Morton, A.B., Palm, R.S. and Balcomb III, K.C. 1998. Dietary specialization in two sympatric populations of killer whales (Orcinus orca) in coastal British Columbia and adjacent waters. Can. J. Zool. 76(8): 1,456-71.

Gannon, D.P., Read, A.J., Craddock, J.E. and Mead, J.G. 1997. Stomach contents of long-finned pilot whales (Globicephala melas) stranded on the US mid-Atlantic coast. Mar. Mamm. Sci. 13(3): 405-18.

Hastie, G.D., Wilson, B., Wilson, J.L., Parsons, K.M. and Thompson, P.M. 2004. Functional mechanisms underlying cetacean distribution patterns: hotspots for bottlenose dolphins are linked to foraging. Marine Biology 144: 397-403.

Hauser, D.W., VanBlaricom, G.R., Holmes, E.E. and Osborne, R.W. 2006. Evaluating the use of whalewatch data in determining killer whale (Orcinus orca) distribution patterns. J. Cetacean Res. Manage. 8(3): 27381.

Hochachka, W.M., Fink, D., Hutchinson, R.A., Sheldon, D., Wong, W. and Kelling, S. 2012. Data-intensive science applied to broad-scale citizen science. Trends Ecol. Evol. 27: 130-37.

Kahle, D. and Wickham, H. 2013. ggmap: Spatial visualisation with ggplot2. The R Journal 5: 144-61.

Lammers, M.O. 2004. Occurrence and behaviour of Hawaiiann spinner dolphins (Stenella longirostris) along Oahu's leeward and south shores. Aquatic Mammals 30: 237-50.

MacLeod, C.D., Bannon, S.M., Pierce, G.J., Schweder, C., Learmouth, J.A., Herman, J.S. and Reid, R.J. 2005. Climate change and the cetacean community of north-west Scotland. Biological Conservation 124(4): 477-83.

Mahaffy, S.D., Baird, R.W., Mcsweeney, D.J., Webster, D.L. and Schorr, G.S. 2015. High site fidelity, strong associations, and long-term bonds: Short-finned pilot whales off the island of Hawai'i. Mar. Mamm. Sci. 31: 1427-51. 
McCluskey, S.M. and Lewison, R.L. 2008. Quantifying fishing effort: A synthesis of current methods and their applications. Fish Fish 9: 188200 .

McConnell, B.J., Beaton, R., Bryant, E., Hall, A.J. and Lovell, P. 2004. Phoning home - a novel mark-recapture/telemetry system based on GSM technology. Mar. Mamm. Sci. 20(2): 274-83. [Paper presented to the 17th Conference of the European Cetacean Society, 9-13 March 2003, Las Palmas de Gran Canaria]

Mignucci-Giannoni, A.A., Montoya-Ospina, R.A., Jimenez-Marrero, N.M., Rodriguez-Lopez, M.A., Williams, E.H. and Bonde, R.K. 2000. Manatee mortality in Puerto Rico. Environ. Manage. 25: 189-98.

Mignucci-Giannoni, A.A., Pinto-Rodríguez, B., Velasco-Escudero, M., Montoya-Ospina, R.A., Jiménez-Marrero, N.M., Rodríguez-Lopéz, M.A., Williams, E.H. and Odell, D.K. 1999. Cetacean strandings in Puerto Rico and the Virgin Islands. J. Cetacean Res. Manage. 1(2): 19198.

Norris, K.S. and Dohl, T.P. 1980. Behavior of the Hawaiian spinner dolphin, Stenella longirostris. Fish. Bull. US 77(4): 821-49.

Norris, K.S., Würsig, B., Wells, R.S. and Würsig, M. 1994. The Hawaiian Spinner Dolphin. University of California Press, Berkeley, California. 408pp.

Pauly, D., Trites, A.W., Capuli, E. and Christensen, V. 1998. Diet composition and trophic levels of marine mammals. ICES J. Mar. Sci 55: 467-81.

Pierpoint, C., Allan, L., Arnold, H., Evans, P., Perry, S., Wilberforce, L. and Baxter, J. 2009. Monitoring important coastal sites for bottlenose dolphin in Cardigan Bay, UK. J. Mar. Biol. Assoc. UK 89: 1033-43.
Reid, S.B., Hirota, J., Young, R.E. and Hallacher, L.E. 1991. Mesopelagicboundary community in Hawaii: Micronekton at the interface between neritic and oceanic ecosystems. Marine Biology 109: 427-40.

Robinson, O.J., Ruiz-Gutierrez, V. and Fink, D. 2018. Correcting for bias in distribution modeling for rare species using citizen science data. Divers. Distrib. 24: 460-72.

Schorr, G.S., Baird, R.W., Hanson, M.B., Webster, D.L., McSweeney, D.J. and Andrews, R.D. 2009. Movements of satellite-tagged Blainville's beaked whales off the island of Hawai'i. Endangered Species Research 10: 203-13.

Shallenberger, E.W. 1981. The Status of Hawaiian Cetaceans. NTIS for the US Marine Mammal Commission, Washington, DC. 79pp.

Thiel, M., Penna-Diaz, M.A., Luna-Jorquera, G., Salas, S., Sellanes, J. and Stotz, W. 2014. Citizen scientists and marine research: volunteer participants, their contributions, and projection for the future. Oceanogr. Mar. Biol. 52: 257-314.

Thorne, L.H., Johnston, D.W., Urban, D.L., Tyne, J., Bejder, L., Baird, R.W., Yin, S., Rickards, S.H., Deakos, M.H., Mobley, J.R., Pack, A.A. and Hill, M.C. 2012. Predictive modeling of spinner dolphin (Stenella longirostris) resting habitat in the main Hawaiian islands. PLOS ONE 7: e43167.

Van Cise, A.M., Martien, K.K., Mahaffy, S.D., Baird, R.W., Webster, D.L., Fowler, J.H., Oleson, E.M. and Morin, P.A. 2017. Familial social structure and socially driven genetic differentiation in Hawaiian short-finned pilot whales. Mol. Ecol.: DOI: 10.1111/mec.14397.

Weinrich, M.T., Kenney, R.D. and Hamilton, P.K. 2000. Right whales (Eubalaena glacialis) on Jeffreys Ledge: A habitat of unrecognized importance? Mar. Mamm. Sci. 16: 326-37. 